\title{
Emergência de plântulas de uma matriz de Campomanesia adamantium (Cambess.) O. Berg, sob diferentes condições
}

\author{
Kaila Ressel * \\ Matheus de Souza Lima-Ribeiro \\ Edésio Fialho dos Reis \\ Universidade Federal de Goiás \\ Cidade Universitária BR 364, km193, nº 3800 \\ CEP 75801-615, Jataí - Goiás, Brasil \\ * Autor para correspondência \\ kailarp@gmail.com
}

Submetido em 04/09/2013

Aceito para publicação em 11/08/2014

\section{Resumo}

Os indivíduos de Campomanesia adamantium são arbustos com bagas arredondadas, amareladas quando maduras, com polpa suculenta, adocicada e aromática. Muito apreciadas pela população do centro-oeste brasileiro, além do potencial econômico, as gabirobeiras possuem importante função ecológica e medicinal. Os poucos registros sobre os métodos de propagação de $C$. adamantium demonstram respostas variadas do processo germinativo, por vezes em condições semelhantes. Objetivou-se com este estudo avaliar a influência de diferentes substratos e métodos de extração da polpa das sementes, sobre a emergência de plântulas de $C$. adamantium, coletadas de um único indivíduo. O experimento fundamentou-se em quatro métodos de extração da polpa a) controle: sementes semeadas com polpa; b) sementes cuja polpa foi retirada mecanicamente pelo atrito com serragem fina; c) sementes cuja polpa foi retirada com lavagem em água corrente; d) sementes com polpa embebidas por $24 \mathrm{~h}$; e, quatro substratos para o plantio: 1) Vermiculita; 2) Plantmax ${ }^{\circledR}$; 3) Tri-Mix ${ }^{\circledR}$; 4) areia média lavada. O substrato areia apresentou o melhor potencial de emergência. Não houve diferença significativa entre os métodos de extração de polpa. A presença da polpa não representou perdas no potencial de emergência, tempo médio ou velocidade média de emergência.

Palavras-chave: Cerrado; Extração de polpa; Gabiroba; Substratos

\section{Abstract}

Seedling emergence of an array of Campomanesia adamantium (Cambess.) O. Berg, under different conditions. Campomanesia adamantium are shrubs with berries that are yellow when ripe, with sweet, aromatic and juicy pulp. The fruits are very appreciated by the Midwestern Brazilian population because, beyond the economic potential, gabirobeiras have important ecological and medicinal applications. The few reports concerning methods of $C$. adamantium propagation demonstrate varied responses of the germination process, and variation sometimes occurs for seeds planted under similar conditions. The objective of this study was to evaluate the influence of different substrates and seed pulp extraction methods on seedling emergence of $C$. adamantium. Seeds were collected from a single individual. The experiment tested four methods of seed pulp extraction: a) Control: seeds sown with pulp, b) seeds whose pulp was mechanically removed by friction using 
fine sawdust, c) seeds whose pulp was removed by washing in running water; d) seeds with pulp soaked for 24 h. Four different substrates per pulp extraction type were then used for planting: 1) Vermiculite; 2) Plantmax ${ }^{\circ}$; 3) Tri-Mix $\left.{ }^{\circledR}, 4\right)$ washed medium-grain sand. Sand was the substrate that produced the best result for seedling emergence, however there were no significant differences in seedling emergence between seed processing methods. The presence of seed pulp did not impact percent seedling emergence, nor did it affect average time or speed of seedling emergence.

Key words: Cerrado; Gabiroba; Pulp extraction; Substrates

\section{Introdução}

Campomanesia é um gênero presente do norte da Argentina a Trinidad, da costa do Brasil até os Andes, Peru, Equador e Colômbia (LANDRUM, 1986). Possui 36 espécies conhecidas, sendo 31 da flora brasileira (LIMA et al., 2011; SOBRAL et al., 2013). A última revisão completa para este gênero foi feita por Landrum (1986). Campomanesia adamantium pode ser facilmente diferenciada em campo, devido às folhas aparentemente glabras, sem glândulas perceptíveis; à ausência de tricomas em estruturas como limbo foliar superior, pecíolos, sépalas e botões florais; à grande quantidade de glândulas no hipanto e nos lobos do cálice; ao pedúnculo duas vezes maior que a flor. São arbustos com bagas arredondadas, amareladas quando maduras, com polpa suculenta, adocicada e aromática. Muito apreciadas pela população regional tanto na forma natural, como em doces, sorvetes, sucos e licores. Além do potencial econômico, a espécie possui função medicinal (COUTINHO et al., 2008; PAVAN et al., 2009; FERREIRA et al., 2013; PASCOAL et al., 2014) e ecológica, servindo como fonte de recursos à fauna no início da estação chuvosa.

A Flora Integrada da Região Centro-Oeste (FLORESCER, 2012) apresenta registros de coletas de sete espécies para o estado de Goiás: C. adamantium, C. cavalcantina, C. eugenioides, C. pubescens, $C$. xanthocarpa, C. sessiliflora e C. velutina. Existem poucos registros sobre o ciclo reprodutivo destas espécies, acredita-se que todas sejam alógamas, como C. pubescens e C. velutina (PROENÇA; GIBBS, 1994). Sabe-se que as sementes de $C$. adamantium (MACHADO et al., 1986) e C. pubescens (DOUSSEAU et al., 2011) apresentam curta longevidade, devendo, portanto, serem semeadas logo após a coleta, pois possuem elevado teor de água na maturidade e são intolerantes a dessecação, ou seja, são recalcitrantes. Melchior et al. (2006) recomendam a semeadura logo após a extração dos frutos, porém, Scalon et al. (2009) asseguram alto potencial de emergência para as sementes extraídas dos frutos em até três dias e advertem sobre a perda de viabilidade das sementes armazenadas dentro dos frutos. A recalcitrância pode representar uma ameaça para estas espécies nativas da região do Cerrado do Centro-Oeste Brasileiro. Durante o período de dispersão das sementes, a temperatura máxima média, na região, pode variar de $23,5^{\circ} \mathrm{C}$ a $33,9^{\circ} \mathrm{C}$, por vezes acompanhada por baixa umidade relativa (INMET, 2011), certamente estas espécies requerem, em ambiente natural, nichos com condições específicas para a germinação e formação de plântulas.

Experimentos de germinação para C. adamantium realizados em diferentes condições, de forma geral, apresentaram altas taxas de germinabilidade, porém com uma amplitude considerável (SCALON et al., 2009; OLIVEIRA et al., 2011; DRESCH et al., 2012). Como cada espécie tem suas necessidades físico-químicas específicas para atingir índices elevados de germinação (OLIVEIRA et al., 2006) é necessário avaliar quais as melhores condições de semeadura para cada espécie. Entretanto, para espécies alógamas, supõe-se que este raciocínio possa ser extrapolado para nível de indivíduos com características genotípicas e fenotípicas próprias.

Além disso, dentro de uma mesma espécie, existem variações fenotípicas individuais que podem ter duas origens: variação devido ao ambiente durante o amadurecimento do fruto e desenvolvimento da semente e, variação devido a diferenças genéticas (BESPALHOK et al., 2007). Mesmo para os frutos, de uma mesma matriz, dispersos em um mesmo momento, existem variações como o tamanho, forma, constituições 
bioquímicas, que podem resultar em uma germinação não uniforme. Fatores como, a idade da planta, a posição do fruto na planta, condições ambientais locais, como disponibilidade de água e de nutrientes, estresse por fogo, sombreamento, predação podem contribuir para o surgimento destas variações (GUTTERMAN, 2000).

A alta variabilidade genética devido ao estádio relativamente selvagem, sem domesticação, aliado à alogamia, têm sido apontadas como as grandes causas da variação no processo germinativo intra-especifico (SANTOS, 2007). Dentro deste conceito, o processo germinativo e, a própria formação de plântulas normais podem ser analisados como respostas fenotípicas das espécies. Portanto, observar as respostas do processo germinativo entre meio-irmãos, ou seja, progênies oriundas de uma mesma matriz, em condições ambientais controladas, pode ser útil devido à redução a variabilidade de respostas fenotípicas.

Para os tecnologistas de semente, a germinação é reconhecida como a produção de plântulas normais (BRASIL, 2009). Ao se observar que, frequentemente, sementes colocadas para germinar produziam plântulas muito diferentes quanto à velocidade de crescimento e desenvolvimento, desenvolveu-se a necessidade de avaliar o vigor dos propágulos (CARVALHO; NAKAGAWA, 2000). Os testes de vigor estão divididos em quatro grupos, os físicos, bioquímicos, de resistência e fisiológicos. Os testes fisiológicos são representados pela primeira contagem, índice de velocidade de germinação, classificação do vigor das plântulas, emergência de plântulas, transferência de matéria seca, crescimento de plântulas e teste de exaustão (MARCOS FILHO et al., 1999).

Ao se considerar que os envoltórios das sementes (como o tegumento e o endocarpo) são diploides e de origem totalmente materna (CARDOSO, 2004) podemos supor que aspectos de dormência e de protrusão radicular estejam vinculados à planta parental. Porém, o embrião é diploide, sendo $50 \%$ de origem materna e $50 \%$ de origem paterna e, o endosperma é triploide, sendo dois terços de origem materna e um terço de origem paterna (CARDOSO, 2004) assim a emergência e o desenvolvimento normal das plântulas tem influência tanto da planta parental, como dos genes de origem paterna, e no caso de plantas alógamas, de várias origens paternas. A variabilidade de possibilidades fenotípicas do processo de emergência de plântulas torna-se tão ampla quanto à variabilidade genotípica. Comparações do vigor da emergência de plântulas de sementes meio-irmãs vão além de sugerir melhores condições de propagação para um indivíduo padrão, servem como indicadores do quanto à variabilidade genética esta interferindo no processo de estabelecimento da espécie, quando comparados a outros estudos semelhantes. Estes dados quando extrapolados ao nível de comparação entre matrizes, progênies e procedências, oferecem ao pesquisador dados adicionais em uma fase inicial de um programa de melhoramento ou conservação genética (VALENTINI; PIÑA-RODRIGUES, 1995).

Neste contexto, objetivou-se com este estudo avaliar a influência de diferentes substratos e métodos de extração da polpa das sementes, sobre a emergência de plântulas meio-irmãs de $C$. adamantium.

\section{Material e Métodos}

Os frutos de C. adamantium foram colhidos no final do mês de novembro de 2011, a partir de uma única matriz visando eliminar efeitos de variação entre matrizes na comparação dos tratamentos. Dez frutos, escolhidos aleatoriamente, e suas respectivas sementes, foram utilizados para avaliação de dados biométricos. Sementes com resquícios de polpa aderida foram utilizadas para o cálculo do teor de umidade, utilizando-se o método padrão de estufa a $103 \pm 2^{\circ} \mathrm{C}$ por 17 h (BRASIL, 2009), logo após a extração dos frutos e, após cinco dias de secagem em papel toalha à $20^{\circ} \mathrm{C}$. As sementes murchas, mal formadas e com quaisquer irregularidades foram descartadas. A coleta foi feita em região de Cerrado no município de Jataí, Goiás. Na véspera da data de semeadura a temperatura média no município de Jataí foi de $31^{\circ} \mathrm{C}$ e a umidade relativa de 31\% (INMET, 2011).

O experimento fundamentou-se em quatro métodos de extração da polpa das sementes: 1) controle: sementes semeadas com polpa; 2) sementes cuja polpa foi retirada mecanicamente pelo atrito com serragem fina; 
3) sementes cuja polpa foi retirada com lavagem em água corrente; 4) sementes com polpa embebidas por $24 \mathrm{~h}$; e, quatro substratos para o plantio: 1) Vermiculita; 2) Plantmax $^{\circledR}$; 3) Tri-Mix $^{\circledR}$; 4) areia média lavada. As 1024 sementes foram divididas em 16 tratamentos, cada qual com 64 sementes, conduzidos em delineamento inteiramente casualizado, em esquema fatorial $4 x 4$. Para a semeadura, cada tratamento foi subdividido em quatro linhas, cada qual com 16 células, distribuídas de forma aleatória nas bandejas de isopor. $\mathrm{O}$ experimento foi conduzido com irrigação periódica, em casa de vegetação da Universidade Federal de Goiás, Campus Jataí.

Como de todas as matrizes avaliadas, nenhuma forneceu um número suficiente de sementes íntegras e bem formadas que satisfizessem às normas gerais das Regras de Análises de Sementes, nem tão pouco estas fornecem protocolos para o gênero (BRASIL, 2009), optou-se pela metodologia sugerida por Carvalho et al. (2005). Estes autores comprovaram a eficiência metodológica de análises estatísticas para experimentos de germinação baseados em pequenas amostras, com até 50 sementes por tratamento.

Através desta metodologia foram avaliados o percentual de emergência (G), o tempo médio de emergência (tm) adaptado de Labouriau (1983) e a velocidade média de emergência (vm) adaptada de Labouriau (1970). Como a proporção de plântulas emergidas é uma variável discreta, utilizou-se a aproximação da distribuição binomial pela normal, para a possível comparação, aos pares, através da distribuição $t$ de "Student". O uso desta aproximação ocorre quando $n_{1} p_{1}>5, n_{1} q_{1}>5, n_{2} p_{2}>5$ e $n_{2} q_{2}>5$, sendo $p_{1}=\mathrm{X}_{1} / n_{1} ; q_{1}=1-p_{1} ; p_{2}=\mathrm{X}_{2} / n_{2}$ e $q_{2}=1-p_{2}$, onde $p_{1}$ e $p_{2}$, as estimativas das proporções de plântulas emergidas no primeiro e segundo tratamentos, respectivamente; $\mathrm{X}_{1}$ e $\mathrm{X}_{2}$ o número de plântulas emergidas no primeiro e segundo tratamentos, respectivamente; $n_{1}$ e $n_{2}$, o número de núculas do primeiro e segundo tratamentos, respectivamente (CARVALHO et al., 2005).

O experimento se estendeu por 65 dias, o potencial de emergência $(\mathrm{G})$ foi contabilizado após a total expansão das folhas cotiledonares. Foram denominadas plântulas normais aquelas que apresentaram o desenvolvimento ereto do hipocótilo e a expansão normal do par cotiledonar. As anormalidades de plântulas, mais comuns, foram o desenvolvimento espiralado do hipocótilo e o subdesenvolvimento das folhas cotiledonares. Adicionalmente, avaliou-se a sobrevivência das plântulas ao déficit hídrico, por substrato, interrompendo-se a irrigação por $24 \mathrm{~h}$, aos $54^{\circ}$ e $64^{\circ}$ dias após o início da emergência. Quatro dias após estes dois eventos foram realizadas as contagens dos indivíduos mortos em cada substrato. A eficiência dos substratos e dos métodos de extração de polpa sobre a emergência e sobrevivência das plântulas foi avaliada através da Análise de Variância (ANOVA). A comparação de médias foi feita pelo teste de Tukey.

\section{Resultados}

Os frutos avaliados de C. adamantium apresentaram, em média, 1,6 cm de diâmetro, 1,4 cm de comprimento e 3,7 sementes por fruto. As sementes apresentaram, em média, 0,5 $\mathrm{cm}$ de largura, 0,4 $\mathrm{cm}$ de comprimento. O teor de umidade para sementes recém extraídas dos frutos foi de $69,7 \%$ e daquelas secas por cinco dias foi de $6,5 \%$.

A emergência de plântulas de Campomanesia adamantium iniciou-se 35 dias após a semeadura, resultando em plântulas fanero-epígeo-foliáceas (RESSEL et al., 2004). Houve a formação de 560 (54,7\%) plântulas normais e $93(9,1 \%)$ plântulas anormais. Não houve relação entre o desenvolvimento anormal de plântulas com qualquer tratamento. $\mathrm{O}$ tempo médio de emergência, do experimento como um todo, foi de 43 dias e a velocidade média de emergência 0,022 $\operatorname{dia}^{-1}$.

O potencial de emergência de plântulas de $C$. adamantium demonstrou uma grande variação entre os tratamentos, de 7,8\% (substrato TriMix ${ }^{\circledR}$, sementes embebidas em água por 24 h) a 89,1\% (substrato areia, sementes com polpa). A interação entre métodos de extração de polpa das sementes e substratos foi não significativa (Tabela 1), indicando que não há vantagens para o potencial de emergência ao se combinar esses dois fatores. O único tratamento que apresentou vantagens significativas foi o substrato areia, com $87 \%$ 
de emergência (Tabela 2). Vermiculita, Plantmax ${ }^{\circledR}$ e Tri-Mix ${ }^{\circledR}$ não apresentaram diferenças significativas em relação à formação de plântulas. Não houve diferença significativa entre os tratamentos de extração de polpa das sementes (Tabela 2).

TABELA 1: Comparação, entre tratamentos, do potencial de emergência $(\mathrm{G})$, tempo médio de emergência $(\mathrm{Tm})$ e velocidade média de emergência $(\mathrm{Vm})$ de Campomanesia adamantium.

\begin{tabular}{lccccccc}
\hline & & \multicolumn{2}{c}{$\mathbf{G}(\%)$} & \multicolumn{2}{c}{ Tm (dia) } & \multicolumn{2}{c}{ Vm $\left(\mathbf{d i a}^{-1}\right)$} \\
\cline { 2 - 8 } & & $\mathbf{F}$ & $\mathbf{P}$ & $\mathbf{F}$ & $\mathbf{P}$ & $\mathbf{F}$ & $\mathbf{P}$ \\
\hline Substrato & 3 & 4,30 & 0,009 & 0,67 & 0,58 & 3,16 & 0,03 \\
Método & 3 & 2,91 & 0,040 & 2,27 & 0,09 & 1,15 & 0,34 \\
Interação & 9 & 1,60 & 0,140 & 0,73 & 0,68 & 0,56 & 0,83 \\
\hline
\end{tabular}

Os resultados obtidos através da análise de déficit hídrico demonstraram que a menor mortalidade de plântulas ocorreu no substrato Plantmax ${ }^{\circledR}$ (Tabela 3). Não houve diferenças significativas de mortalidade, por déficit hídrico, entre areia, Vermiculita ${ }^{\circledR}$ e Tri-Mix ${ }^{\circledR}$.

TABELA 2: Potencial de emergência $(G)$, tempo médio de emergência $(\mathrm{Tm})$ e velocidade média de emergência $(\mathrm{Vm})$ em relação aos substratos e métodos de extração da polpa de sementes de Campomanesia adamantium.

\begin{tabular}{lccc}
\hline Substratos & $\begin{array}{c}\text { G } \\
(\%)\end{array}$ & $\begin{array}{c}\text { Tm } \\
(\text { dia })\end{array}$ & $\begin{array}{c}\text { Vm } \\
\left(\text { dia }^{-1}\right)\end{array}$ \\
\hline Vermiculita & $41,8 b^{*}$ & $42^{\mathrm{a}}$ & $0,021 \mathrm{ab}$ \\
Tri-Mix $^{\circledR}$ & $36,7 \mathrm{~b}$ & $44 \mathrm{a}$ & $0,020 \mathrm{a}$ \\
Plantmax $^{\circledR}$ & $53,5 \mathrm{~b}$ & $44 \mathrm{a}$ & $0,023 \mathrm{ab}$ \\
Areia & $86,7 \mathrm{a}$ & $41 \mathrm{a}$ & $0,024 \mathrm{~b}$ \\
\hline Extração de polpa & & & \\
\hline Controle: Sementes com polpa & $59,8 \mathrm{a}$ & $44 \mathrm{a}$ & $0,023 \mathrm{a}$ \\
Método com serragem & $64,8 \mathrm{a}$ & $45 \mathrm{a}$ & $0,022 \mathrm{a}$ \\
Método com água corrente & $50,8 \mathrm{a}$ & $44 \mathrm{a}$ & $0,023 \mathrm{a}$ \\
Método com embebição & $43,4 \mathrm{a}$ & $38 \mathrm{a}$ & $0,020 \mathrm{a}$ \\
\hline
\end{tabular}

* Médias seguidas de mesma letra na coluna não diferem ao nível de significância de 5\% pelo teste Tukey.
TABELA 3: Porcentagem de plântulas mortas de Campomanesia adamantium após déficit hídrico por substrato $\left(\mathrm{F}_{(3,47)}=4,3, \mathrm{p}=0,009\right)$.

\begin{tabular}{lc}
\hline \multicolumn{1}{c}{ Substratos } & M $(\%)$ \\
\hline Vermiculita & $25,2 \mathrm{a}^{*}$ \\
Tri-Mix $^{\circledR}$ & $15,6 \mathrm{a}$ \\
Plantmax $^{\circledR}$ & $4,4 \mathrm{~b}$ \\
Areia & $23,4 \mathrm{a}$ \\
\hline
\end{tabular}

* Médias seguidas de mesma letra não diferem ao nível de significância de 5\% pelo teste Tukey.

\section{Discussão}

Os frutos dimensionados corresponderam, em tamanho, à maioria dos frutos avaliados por Melchior et al. (2006) e foram menores que os avaliados por Oliveira et al. (2011), porém apresentaram um número maior de sementes por fruto, que o observado em ambos os trabalhos. O teor de umidade para sementes recém extraídas dos frutos de C. adamantium, foi maior que os $57 \%$ observados por Dresch et al. (2012) para a mesma espécie e maior que o teor de $42 \%$ de $C$. pubescens (DOUSSEAU et al., 2011). A forte redução do teor de umidade, dias após a extração, também ocorreu, como em outros estudos similares (MALUF; PISCIOTTANOEREIO, 2005; MELCHIOR et al., 2006; DOUSSEAU et al., 2011; DRESCH et al., 2012).

Os resultados da emergência de plântulas de $C$. adamantium obtidos por Oliveira et al. (2011) foram melhores que os deste trabalho. Tanto as porcentagens de emergência como as de formação de plântulas normais foram maiores, assim como, as médias de tempo e velocidade de emergência demonstraram maior eficiência.

Os resultados, da Tabela 2, demonstraram que a polpa das sementes manteve o padrão observado por estudos com amostras mistas, ou seja, não representou um fator limitante para a germinação, nem tão pouco, interfere na emergência de plântulas. Melchior et al. (2006) e Oliveira et al. (2011) obtiveram germinação acima de $80 \%$ em sementes de $C$. adamantium com polpa, inclusive descartaram a necessidade do uso do processo de fermentação recomendado por Carmona et al. (1994) para a extração das sementes. Scalon et 
al. (2009) obtiveram 90\% de germinação de sementes de $C$. adamantium, com métodos de extração da polpa, entretanto, sem diferenças significativas entre os mesmos.

Assim como o presente estudo registrou diferenças no potencial de emergência de plântulas ao se variar o substrato (Tabela 2), Maluf e Pisciottano-Ereio (2005) e Dousseau et al. (2011) também as observaram em relação ao potencial de germinação. Dousseau et al. (2011) encontraram as maiores porcentagens de germinação nos substratos areia e papel e menores em Vermiculita para $C$. pubescens. Ao contrário do encontrado por Maluf e Pisciottano-Ereio (2005) que obtiveram os melhores resultados de germinação para C. phaea em Vermiculita. A Vermiculita é um substrato com alta retenção de água, ao contrário da areia, um substrato com alta capacidade de drenagem. Sendo C. phaea uma espécie nativa de Mata Atlântica é natural que uma maior umidade do substrato seja desejável, ao contrário de C. pubescens e C. adamantium espécies de Cerrado, nativas de solos arenosos e drenados.

Apesar das altas taxas de germinação e formação de plântulas de C. adamantium, os estudos realizados apresentaram algumas diferenças. No atual trabalho o substrato areia apresentou porcentagens de emergência significativamente maiores que outros substratos, como Vermiculita e Plantmax. Oliveira et al. (2011) registraram valores ainda maiores com o substrato composto de Plantmax e Vermiculita (v:v). Scalon et al. (2009) alcançaram altas taxas de germinação com os substratos papel e Plantmax. Assim como, Melchior et al. (2006) e Dresch et al. (2012) para papel e Dousseau et al. (2011) para papel e areia. Além disso, a resposta inferior apresentada pelas sementes lavadas em água corrente e embebidas por $24 \mathrm{~h}$ neste estudo, foi diferente a apresentada por Scalon et al. (2009) para os mesmos métodos.

É certo que estudos como este, que visem compreender a propagação de espécies nativas são fundamentais. No entanto, compreender a biologia reprodutiva de tais espécies se faz urgente. A espécie estudada faz parte do Complexo Xanthocarpa assim como as espécies $C$. xanthocarpa, $C$. aromatica, $C$. reitzii, C. velutina, $C$. eugenioides, $C$. pubescens, $C$. pabstiana e C. aurea (LANDRUN, 1986). Destas, cinco ( $C$. adamantium, $C$. velutina, $C$. eugenioides, $C$. pubescens, $C$. xanthocarpa) co-ocorrem nos campos de Cerrado de Goiás (FLORESCER, 2012) sem nenhum tipo de isolamento físico à reprodução. Todas com floração concomitante pelo menos no mês de outubro, segundo registros de herbários (FLORESCER, 2012) e são polinizadas pelos mesmos vetores (PROENÇA; GIBBS, 1994). Alem disso, sabe-se que C. pubescens e C. velutina, por exemplo, são espécies autocompatíveis, porém, a maior parte das fecundações ocorre por polinização cruzada (PROENÇA; GIBBS, 1994; TOREZAN-SILINGARD; DEL-CLARO, 1998). Desta forma, é possível supor que as espécies co-ocorrentes possam trocar genes livremente e que, características que as identificam como espécies possam estar se perdendo (JUDD et al., 2009). Podemos supor que, como C. pubescens forma híbridos com outras espécies cogenéricas, além de C. xanthocarpa (LANDRUM, 1986), isto possa estar ocorrendo com outras espécies próximas, conferindo características genotípicas e fenotípicas peculiares a cada indivíduo das espécies em questão.

Adicionalmente, há de se considerar que espécies alógamas podem apresentar altos índices de heterozigose, isto tem sido observado em muitas populações naturais de frutíferas tropicais (MELO JÚNIOR et al., 2004; GOIS et al., 2009; SILVA et al., 2009; GONÇALVES et al., 2010). De acordo com Sebbenn et al. (2000), os elevados níveis de heterozigosidade são extremamente importantes porque torna possível a ocorrência de um grande número de novas combinações genotípicas, aumentando o potencial evolutivo da espécie, bem como a capacidade de se adaptar às alterações ambientais. Como foi observado por Ganga et al. (2010) e Martins et al. (2012), para populações da espécie Hancornia speciosa. Neste contexto, os indivíduos da espécie podem apresentar respostas fenotípicas diferenciadas a tratamentos de propagação. Como esta avaliação baseouse na propagação de sementes meio-irmãs, sugere-se, a partir deste ponto inicial, a comparação entre matrizes e procedências da mesma espécie para a certificação dos melhores procedimentos, com a vantagem de se direcionar as poucas sementes a tratamentos mais específicos. 
Em relação à mortalidade das plântulas sob déficit hídrico, os resultados demonstraram que o tempo de exposição ao estresse igualou os substratos em termos de capacidade de retenção de água (CRA). Os substratos comerciais utilizados apresentam, segundo seus fabricantes, altas porcentagens de CRA, Plantmax ${ }^{\circledR}$ $(100 \%)$, Tri-Mix $^{\circledR}(150 \%)$, Vermiculita (490 a 629\%), ao contrário da areia. Entretanto, pôde-se observar que não houve diferenças significativas de mortalidade por déficit hídrico entre areia, Vermiculita ${ }^{\circledR}$ e Tri-Mix ${ }^{\circledR}$.

É possível que a menor mortalidade no substrato Plantmax $^{\circledR}$ tenha ocorrido devido à presença de um manto de cianobactérias, verde-escuro, que só se formou, homogeneamente, neste substrato. Muitas espécies de cianobactérias podem colonizar habitats aéreos ou subaerofíticos, formando biofilmes, ou mantos caracterizados pela formação de placas densas e coesas aderidas ao substrato (JORGENSEN et al., 1979). Este manto é comum em cianobactérias coloniais, que têm suas células unidas por uma bainha ou envoltório mucilaginoso. Esta estrutura gelatinosa, dentre suas funções, evita a dessecação da colônia. Este manto, quando ressecado, formou uma crosta sobre o substrato que, provavelmente, reduziu a perda excessiva de água por evaporação, o que possivelmente possibilitou melhores condições de sobrevivência às plântulas.

\section{Agradecimentos}

À Coordenação de Aperfeiçoamento de Pessoal de Nível Superior/ CAPES pelo suporte financeiro através do Programa Nacional de Pós-Doutorado (PNPD).

\section{Referências}

BESPALHOK, F. J. C.; GUERRA, E. P.; OLIVEIRA, R. Noções de Genética Quantitativa. In: BESPALHOK F. J. C.; GUERRA, E. P.; OLIVEIRA, R. (Ed.). Melhoramento de plantas. 2007. Disponível em <http:/www.bespa.agrarias.ufpr.br/paginas/livro/ capitulo\%205.pdf.>. Acesso em: 16 maio 2014

BRASIL - MINISTÉRIO DA AGRICULTURA, PECUÁRIA E ABASTECIMENTO. SECRETARIA DE DEFESA AGROPECUÁRIA. Regras para análise de sementes. Brasília: MAPA/ ACS, 2009. 399 p.

CARDOSO, V. J. M. Domência: estabelecimento do processo. In: FERREIRA, A. G.; BORGHETTI, F. (Ed.). Germinação, do básico ao aplicado. Porto Alegre: Artmed, 2004. p. 95-108.
CARMONA, R.; REZENDE, L. P.; PARENTE, T. V. Extração química de sementes de gabiroba (Campomanesia adamantium Camb.). Revista Brasileira de Sementes, Londrina, v. 16, n. 1, p. 31-33, 1994.

CARVALHO, M.; SANTANA, D. G.; RANAL, M. A. Emergência de plântulas de Anacardium humile A. St.-Hil. (Anacardiaceae) avaliada por meio de amostras pequenas. Revista Brasileira de Botânica, São Paulo, v. 28, n. 3, p. 627-633, 2005.

CARVALHO, N. M.; NAKAGAWA, J. Sementes: ciência, tecnologia e produção. Jaboticabal: FUNEP, 2000. 588 p.

COUTINHO, D.; COELHO, R. G.; KATAOKA, V. M. F.; HONDA, N. K.; SILVA, J. R. M.; VILEGAS, W.; CARDOSO, C. A. L. Determination of phenolic compounds and evaluation of antioxidant capacity of Campomanesia adamantium leaves. Eclética Química, São Paulo, v. 33, n. 4, p. 53-60, 2008.

DOUSSEAU, S.; ALVARENGA, A. A.; GUIMARÃES, R. M.; LARA, T. S.; CUSTÓDIO, T. N.; CHAVES, I. S. Ecofisiologia da germinação de sementes de Campomanesia pubescens. Ciência Rural, Santa Maria, v. 41, n. 8, p. 1362-1368, 2011.

DRESCH, D. M.; SCALON, S. P. Q.; MASETTO, T. E.; VIEIRA, M. C. Germinação de sementes de Campomanesia adamantium (Camb.) O. Berg em diferentes temperaturas e umidades do substrato. Scientia Forestalis, Piracicaba, v. 40, n. 94, p. 223-229, 2012.

FERREIRA, L. C.; GRABE-GUIMARÃES, A.; DE PAULA, C. A.; MICHEL, M. C. P.; GUIMARÃES, R. G.; REZENDE, S. A.; DE SOUZA FILHO, J. D. ; SAÚDE-GUIMARÃES, D. A. Antiinflammatory and antinociceptive activities of Campomanesia adamantium. Journal of Ethnopharmacology, Leiden, v. 145, n. 1, p. 100-108, 2013.

FLORESCER. Flora integrada da região Centro-Oeste: banco de dados 2012. 2012. Disponível em: <http://www.florescer.unb.br>. Acesso em: 11 mar. 2013.

GANGA, R. M. D.; FERREIRA, G. A.; CHAVES, L. J.; NAVES, R.V.; NASCIMENTO, J. L. Caracterização de frutos e árvores de populações naturais de Hancornia speciosa Gomes do Cerrado. Revista Brasileira de Fruticultura, Jaboticabal, v. 32, p. 101-103, 2010.

GOIS, I. B.; SILVA-MANN, R.; FERREIRA, R. A. Variabilidade genética de Spondias lutea L. em uma população do baixo São Francisco sergipano, por meio de isoenzimas. Scientia Forestalis, Piracicaba, v. 37, p. 55-60, 2009.

GONÇALVES, A. C.; VIEIRA, A. F.; REIS, C. A. F.; CARVALHO, D. Conservação de Dimorphandra mollis Benth. (Fabaceae) baseada na estrutura genética de populações naturais. Revista Árvore, Viçosa, v. 34, p. 95-101, 2010.

GUTTERMAN, Y. Maternal effects on seeds during development. In: FENNER, M. (Ed.). Seeds: the ecology of regeneration in plant communities. 2. ed. London: CABI Publishing, 2000. p. 59-84.

INMET - INSTITUTO NACIONAL DE METEREOLOGIA. Banco de dados de Jataí. 2011. Disponível em: <http:/www. inmet.gov.br>. Acesso em: 11 mar. 2013.

JORGENSEN, B. B.; REVSBECH, N. P.; BLACKBURN, T. H.; COHEN, Y. Diurnal cycle of oxygen and sulfide microgradients and microbial photosynthesis in a cyanobacterial mat sediment. Applied and Environmental Microbiology, Washington, v. 38, p. 38-56, 1979. 
JUDD, W. S.; CAMPBELL, C. S.; KELLOGG, E.; STEVENS, P. Sistemática vegetal: um enfoque filogenético. Porto Alegre: Artmed, 2009. 632 p.

KAWASAKI, M. L. Flora da Serra do Cipó, Minas Gerais: Myrtaceae. Boletim de Botânica da Universidade de São Paulo, São Paulo, v. 11, p. 121-170, 1989.

LABOURIAU, L. G. On the physiology of seed germination in Vicia graminea. Anais da Academia Brasileira de Ciências, Rio de Janeiro, v. 42, p. 235-262, 1970.

LABOURIAU, L. G. A germinação das sementes. Washington: Secretaria Geral da OEA, 1983. 174 p.

LANDRUM, L. R. Campomanesia, Pimenta, Blepharocalyx, Legrandia, Acca, Myrrhinium, and Luma (Myrtaceae). Flora Neotropica, Nova York, v. 45, p. 1-178, 1986.

LANDRUM, L. R. Two new species of Campomanesia (Myrtaceae) from Espírito Santo and Bahia, Brazil. Brittonia, Nova York, v. 53, n. 4 , p. $534-538,2001$.

LIMA, D. F.; GOLDENBERG, R.; SOBRAL, M. O gênero Campomanesia no estado do Paraná, Brasil. Rodriguésia, Rio de Janeiro, v. 62, n. 3, p. 683-693, 2011.

MACHADO, J. W. B.; PARENTE, T. V.; LIMA, R. M. Informações sobre a germinação e características físicas das sementes de fruteiras nativas do Distrito Federal. Revista Brasileira de Fruticultura, Jaboticabal, v. 8, n. 2, p. 59-62, 1986.

MALUF, A. M.; PISCIOTTANO-EREIO, W. A. Secagem e armazenamento de sementes de cambuci. Pesquisa Agropecuária Brasileira, Brasília, v. 40, n. 7, p. 707-714, 2005.

MARCOS FILHO, J.; SILVA, W. R.; NOVEMBRE, A. D. C.; CHAMMA, H. M. C. P. Estudos comparativos de métodos para avaliação da qualidade fisiológica de sementes de soja, com ênfase ao teste de condutividade elétrica. Pesquisa Agropecuária Brasileira, Brasília, v. 25, n. 12, p. 1805-1815, 1990.

MARTINS, G.V.; MARTINS, L. S. S.; VEASEY, E. A.; LEDERMAN, I. E.; SILVA, E. F. Diversity and genetic structure in natural populations of Hancornia speciosa Var. speciosa Gomes in Northeastern Brazil. Revista Brasileira de Fruticultura, v. 34, n. 4, p. 1143-1153, 2012.

MELCHIOR, S. J.; CUSTÓDIO, C. C.; MARQUES, T. A.; MACHADO NETO, N. B. Colheita e armazenamento de sementes de gabiroba (Campomanesia adamantium Camb. - Myrtaceae) e implicações na germinação. Revista Brasileira de Sementes, Londrina, v. 28, n. 3, p. 141-150, 2006.

MELO JUNIOR, A. F.; CARVALHO, D.; PÓVOA, J. S. R.; BEARZOLI, E. Estrutura genética de populações naturais de pequizeiro (Caryocar brasiliense Camb). Scientia Forestalis, Piracicaba, v. 66, p. 56-65, 2004.

OLIVEIRA, I. V. M.; CAVALCANTE, I. H. L.; MARTINS, A. B. G. Influência do substrato na emergência de plântulas de sapota preta. Revista Caatinga, Mossoró, v. 19, n. 4, p. 383-386, 2006.

OLIVEIRA, M. C.; SANTANA, D. G.; SANTOS, C. M. Biometria de frutos e sementes e emergência de plântulas de duas espécies frutíferas do gênero Campomanesia. Revista Brasileira de Fruticultura, Jaboticabal, v. 33, n. 2, p. 446-455, 2011
PASCOAL, A. C. R. F.; EHRENFRIED, C. A.; LOPEZ, B. G.; DE ARAUJO, T. M.; PASCOAL, V. D. B.; GILIOLI, R.; ANHÊ, G. F.; RUIZ, A. L. T. G.; CARVALHO, J. E.; STEFANELLO, M. E. A.; SALVADOR, M. J. Antiproliferative activity and induction of apoptosis in PC-3 cells by the chalcone cardamonin from Campomanesia adamantium (Myrtaceae) in a bioactivity-guided study. Molecules, Basel, v. 19, n. 2, p.1843-55, 2014.

PAVAN, F. R.; LEITE, C. Q. F.; COELHO, R. G.; COUTINHO, I. D.; HONDA, N. K.; CARDOSO, C. A. L.; VILEGAS, W.; LEITE, S. R. A.; SATO, D. N. Evaluation of anti-Mycobacterium tuberculosis activity of Campomanesia adamantium (Myrtaceae). Química Nova, São Paulo, v. 32, n. 5, p. 1222-1226, 2009.

PROENÇA, C. E. B.; GIBBS, P. Reproductive biology of eight sympatric Myrtaceae from Central Brazil. New Phytologist, Lancaster, v. 126, p. 343-354, 1994.

RESSEL, K.; GUILHERME, F. A. G.; SCHIAVINI, I.; OLIVEIRA, P. E. Ecologia morfofuncional de plântulas de espécies arbóreas da Estação Ecológica do Panga, Uberlândia, Minas Gerais. Revista Brasileira de Botânica, São Paulo, v. 27, n. 2, p. 311-323, 2004.

SANTOS, F. S. Biometria, germinação e qualidade fisiológica de sementes de Tabebuia chrysotricha (Mart. ex A. DC.) Standl. provenientes de diferentes matrizes. 2007. 48 f. Dissertação (Mestrado em Agronomia) - Universidade Estadual Paulista Julio de Mesquita Filho, Jaboticabal. 2007.

SCALON, S. P. Q.; LIMA, A. A.; SCALON FILHO, H.; VIEIRA, M. C. Germinação de sementes e crescimento inicial de mudas de Campomanesia adamantium Camb.: efeito da lavagem, temperatura e de bioestimulantes. Revista Brasileira de Sementes, Londrina, v. 31, n. 2, p. 96-103, 2009.

SEBBENN, A. M.; KAGEYAMA, P. Y.; SIQUEIRA, A. C. M. F.; ZANATTO, A. C. S. Sistema de cruzamento em populações de Cariniana legalis Mart. O. Ktze.: implicações para a conservação e o melhoramento genético. Scientia Forestalis, Piracicaba, v. 58, p. 25-40, 2000.

SILVA, E. F.; MARTINS, L. S. S.; OLIVEIRA, V. R. Diversity and genetic structure in cajá tree (Spondias mombin L.) populations in Northeastern Brazil. Revista Brasileira de Fruticultura, Jaboticabal, v. 31, p. 117-181, 2009.

SOBRAL, M.; PROENÇA, C.; SOUZA, M.; MAZINE, F.; LUCAS, E. Lista de Espécies da Flora do Brasil - Myrtaceae. 2013. Disponível em: $<$ http://floradobrasil.jbrj.gov.br $>$. Acesso em: 11 mar. 2013.

TOREZAN-SILINGARD, H. M.; DEL-CLARO, K. Behavior of visitors and reproductive biology of Campomanesia pubescens (Myrtaceae) in Cerrado vegetation. Ciência e Cultura, São Paulo, v. 50, p. 281-284, 1998.

VALENTINI, S. R. T.; PINÃ-RODRIGUES, F. C. M. Aplicação do teste de vigor em sementes: In: SILVA, A.; PINÃ-RODRIGUES, F. C. M.; FIGLiOLIA, M. B. (Ed.). Manual técnico de sementes florestais. São Paulo: Instituto Florestal, 1995. p. 74-84. 